\title{
REVIEW
}

\section{Management of neuropathic pain following spinal cord injury: now and in the future}

\author{
PJ Siddall
}

Pain Management Research Institute, Royal North Shore Hospital, University of Sydney, Sydney, New South Wales, Australia

\begin{abstract}
Objective: To provide an overview of our current understanding of the problem of neuropathic pain following spinal cord injury $(\mathrm{SCl})$ and to suggest possible therapeutic options in the near future. Methods: Original research articles, reviews and book chapters on the subject of pain and $\mathrm{SCl}$. Results: Neuropathic pain following SCI has presented a challenge not only for traditional concepts of how pain occurs but also for more recent conceptualizations. We have made substantial progress in identifying the common types of pain that occur following $\mathrm{SCl}$, determining the prevalence and characteristics of pain, investigating some of the pathophysiological changes in the nervous system that may contribute to the presence of neuropathic $\mathrm{SCl}$ pain and examining the effectiveness of some treatments. However major challenges remain. We still need to reach consensus on an $\mathrm{SCl}$ pain taxonomy; our understanding of mechanisms and the relative contribution of changes in the periphery, spinal cord and brain is incompletely understood; there are few studies that indicate effective treatment options, particularly for neuropathic SCl pain; and treatment of the biological and psychological contributors to pain is often fragmented.

Conclusion: Recent studies suggest the potential usefulness of new treatment approaches such as selective pharmacological agents, application of novel neurostimulation techniques and the use of cognitive approaches to modify the pain experience. Our increasing understanding of the problem combined with the promise of these new approaches offers hope for improved management of neuropathic pain following $\mathrm{SCl}$ in the near future.
\end{abstract}

Spinal Cord (2009) 47, 352-359; doi:10.1038/sc.2008.136; published online 11 November 2008

Keywords: spinal cord injuries; pain; neuropathic

\section{The problem of pain following $\mathrm{SCI}$}

Pain has increasingly been recognized as an important contributor to suffering, poorer rehabilitation outcomes and reduced quality of life for people with a spinal cord injury (SCI). There are at least three facts that indicate the important impact of pain on the person with SCI. First, pain following SCI is common. Although there is some variability, studies investigating the prevalence of pain in people with SCI indicate that around $65-85 \%$ of those with a spinal injury will experience pain and around one-third of these will have severe pain. ${ }^{1}$

Second, pain following SCI is consistently rated as one of the most difficult problems to manage. ${ }^{2}$ There are a large

Correspondence: Associate Professor PJ Siddall, Pain Management Research Institute, Royal North Shore Hospital, University of Sydney, St Leonards, New South Wales 2065, Australia.

E-mail: phils@med.usyd.edu.au

The Sir Ludwig Guttmann Lecture, and the meeting (47th International Spinal Cord Society Annual Scientific Meeting, Durban, South Africa, 30th August3rd September 2008).

Received 19 August 2008; revised 19 September 2008; accepted 19 September 2008; published online 11 November 2008 number of studies that clearly demonstrate the strong relationship between pain and poorer physical, psychological and social functioning. ${ }^{3-6}$ Pain may adversely affect sleep and participation in activities of daily living and may contribute to functional disability beyond that associated with the loss of mobility. ${ }^{7-9}$ Pain also directly contributes to disability by reducing the person's capacity to participate in rehabilitation and return to work. ${ }^{9-12}$ These effects on functioning flow through to more global indicators of health such as reduced quality of life ${ }^{13-15}$ and life satisfaction. ${ }^{16}$

Third, the long-term prognosis for pain resolution following SCI is often poor. Many people report that pain following their SCI continues or even worsens over time ${ }^{3}$ and it has been documented that those reporting neuropathic pain in the subacute period (3-6 months) after injury are likely to continue experiencing pain at 3-5 years following their injury. ${ }^{1}$

Pain therefore presents a major challenge to those with an SCI and subsequently to those involved in their care. This paper will review how our understanding of pain following 
SCI has advanced in recent years, some of the mechanisms that are believed to underlie pain following SCI and current treatment approaches. Rather than trying to deal with all types of pain following SCI, the main focus of this review will be the features, mechanisms and management of neuropathic SCI pain. Lastly, it will look forward to possible future developments and potential treatment approaches in the future.

\section{Looking back}

\section{Descartes and telephone lines}

Before looking at our current understanding and approach to the management of pain following SCI, it is interesting to look back and see how far we have come. Going back to the seventeenth century, our concept of pain was very much in line with the views of the French philosopher, mathematician and scientist, René Descartes. Descartes put forward a conceptual framework for pain that hypothesized that pain was transmitted from the periphery along specific pain fibres and up the spinal cord to arrive in the brain and activate a pain region that was associated with pain perception.

Whether correctly interpreted or not, this conceptual framework had a wide impact that included our conceptualization of pain following SCI. On the basis of this concept of passive transmission of sensation along telephone wires, some people believed that people with an SCI could not be experiencing real pain as clearly if they had no sensation, indicating that the wires were cut, how could they then experience pain?

We now know that this misconception of the nervous system as a passive transmitter of sensory information is false. Sadly, if you transect the spinal cord surgically, many people develop new pain in the area below the transection within 6-12 months. As we now know and shall explore further later, recent findings from mechanistic studies clearly indicate that rather than being an inert passive conductor of signals, the nervous system is highly plastic and constantly modifies and reorganizes depending on the nature of sensory inputs. However, it is these attempts to adapt to the level of sensory input that may contribute to the development of pain following an SCI.

\section{The gate theory}

Despite the prominence of Descartes' views, it was clear that his proposed conceptualization of pain had problems. In 1965, two pain researchers, Ronald Melzack and Patrick Wall put forward a concept that was to have a major impact on our understanding of pain. ${ }^{17}$ This concept, which was termed the gate theory, proposed that pain was influenced by the interaction of sensory input in large and small fibres in the dorsal horn of the spinal cord. It is hard to overestimate the impact of this proposed concept on the field of pain. Although not entirely new or correct in its details, it nevertheless provided a clear new conceptual framework for our thinking about pain.

Despite this forward movement in our understanding of pain, it still left several problems unresolved. One of these problems was pain following SCI. In an invited plenary address to the Sixth World Congress of Pain in 1990 to mark 25 years following the publication of the gate theory, Melzack stated, 'There is a set of observations on pain in paraplegics that just does not fit the theory. ${ }^{\prime 18}$ This put out the challenge to find a new conceptualization of pain that allowed not only for modification of peripheral inputs but also ongoing pain despite the apparent complete loss of peripheral inputs. This issue has been a dominant one in trying to understand the mechanisms underlying pain following SCI. As we shall see later, there are fascinating insights from basic research that are starting to provide answers to this difficult question.

\section{Pain terminology}

Another important historical issue in the field of pain following SCI was that of pain terminology. Many observant clinicians over the last century clearly described the pain that occurred following SCI. For example, an account by Feiling that was published in the Proceedings of the Royal Society of Medicine in 1937 very accurately describes the segmental hyperaesthesia that is often observed acutely in people with incomplete cervical cord injuries. ${ }^{19}$

Over time, many clinicians in original articles or book chapters described the different types of pain that were associated with SCI. However, the end result was that by the end of the last century there were nearly as many terms as publications, with very little agreement about which terminology to use. Although it may seem like a relatively unimportant semantic issue, it impeded the ability of clinicians to communicate clearly what sort of pain they were talking about as well as hindering the design and application of findings of clinical trials and the interpretation and translation of a growing number of basic studies investigating pain mechanisms.

\section{Where are we now?}

Fortunately our understanding of pain following SCI has progressed since the days of Descartes. Basic science has identified numerous changes that occur in the nervous system following SCI that may contribute to the development of pain. Although not perfect, we have moved forward in agreeing on pain terminology that has led to enhanced communication among clinicians and researchers and efforts continue to refine this further. And although far from satisfactory, we now have a number of treatments that provide a proportion of people with some benefit. I will examine each of these issues in turn but let me start by looking at the current situation with regard to pain terminology and classification.

\section{Classification of pain following $\mathrm{SCl}$}

As mentioned previously, many different SCI pain classification systems can be found in the literature causing confusion among researchers and clinicians. Some years ago, recognizing the importance of the problem of pain following SCI, the 
Table 1 Proposed IASP classification of pain following $\mathrm{SCl}$

\begin{tabular}{lll}
$\begin{array}{l}\text { Broad type } \\
\text { (Tier 1) }\end{array}$ & $\begin{array}{l}\text { Broad system } \\
\text { (Tier 2) }\end{array}$ & $\begin{array}{l}\text { Specific structures/pathology } \\
\text { (Tier 3) }\end{array}$ \\
\hline Nociceptive & Musculoskeletal & $\begin{array}{l}\text { Bone, joint, muscle trauma } \\
\text { or inflammation } \\
\text { Mechanical instability } \\
\text { Muscle spasm } \\
\text { Secondary overuse syndromes }\end{array}$ \\
& Visceral & $\begin{array}{l}\text { Renal calculus, bowel, sphincter } \\
\text { dysfunction, etc. } \\
\text { Dysreflexic headache }\end{array}$ \\
& Above level & $\begin{array}{l}\text { Compressive mononeuropathies } \\
\text { Complex regional pain syndromes }\end{array}$ \\
& At level & $\begin{array}{l}\text { Nerve root compression (including } \\
\text { cauda equina) } \\
\text { Syringomyelia } \\
\text { Spinal cord trauma/ischemia }\end{array}$ \\
& & Spinal cord trauma/ischemia
\end{tabular}

International Association of the Study of Pain (IASP) established a Spinal Cord Injury Pain Task Force. One of the aims of the Task Force was to put forward a taxonomy or classification of SCI pain that would hopefully act as a starting point in working towards consensus in this area (Table 1). ${ }^{20}$ Although adopted fairly widely, this taxonomy still has limitations and there are ongoing efforts that involve representatives from not only the IASP but also the International Spinal Cord Society and the American Spinal Injury Association to develop a classification system that builds on existing taxonomies and satisfies the needs of clinicians and clinical and basic researchers. ${ }^{21,22}$

Although the terminology differs, current taxonomies broadly identify at least four major types of pain following SCI. These are musculoskeletal and visceral pains and two types of neuropathic pain that appear to be specific to SCI. The first type of neuropathic pain occurs in a dermatomal or segmental distribution at the level of injury and is therefore often referred to as at-level neuropathic pain. The second type of neuropathic pain occurs in a more diffuse distribution below the level of neurological injury and is therefore referred to as below-level neuropathic pain. Some taxonomies have attempted to take this further and identify subtypes linked to specific pathology. Although helpful and desirable, particularly in a research setting, in practice this is often difficult and cumbersome and at present difficult to validate.

\section{Mechanisms of neuropathic pain following $\mathrm{SCl}$}

Early studies in the 1950 s provided clues as to the possible underlying contributing pathophysiological factors involved in neuropathic SCI pain and suggested that the site of the problem may be in the spinal cord close to the site of damage. ${ }^{23,24}$ Further studies since then have confirmed this although there is also emerging evidence to suggest that neuropathic pain may arise from more 'downstream' changes in damaged nerve roots as well as 'upstream' changes in the brain.

\section{Periphery}

The degree to which peripheral changes influence neuropathic SCI pain remains uncertain, particularly in those with clinically complete injuries. Peripheral generators including damage to nerve roots at the level of injury may give rise to pain, particularly in those who have incomplete injuries. People with clinically complete injuries may have residual sensory transmission through the cord that is not detectable using standard physical examination techniques (sometimes referred to as a 'sensory discomplete' lesion). ${ }^{25}$ In this subgroup of electrophysiologically incomplete lesions, pain may be influenced by transmission of nociceptive impulses arising in the periphery through these residual pathways.

\section{Spinal cord}

As mentioned above, some of the earliest investigations into SCI pain noted that in some people blockade of the spinal cord using spinal administration of a local anaesthetic immediately above the level of injury resulted in relief of pain. $^{23,24}$ From these observations, it was proposed that neuropathic SCI pain may be due to the presence of an 'irritated focus' or 'neural pain generator' that was close to the rostral end of the SCI. This was supported by the finding that dorsal horn neurons immediately above the level of SCI demonstrated abnormal spontaneous neuronal activity. ${ }^{26}$

More recently, animal and human studies have confirmed that there are changes in the properties of nerve cells close to the site of SCI. These changes include increased responsiveness to peripheral stimulation, an increase in the level of background activity and prolonged firing following a stimulus. ${ }^{27-29}$ Further studies have demonstrated a number of changes in neurotransmitters and receptors that may lead to an increase in excitation or a reduction in inhibition and result in the change in firing properties of these spinal neurons. These include changes in $N$-methyl-D-aspartate (NMDA), non-NMDA and metabotropic glutamate receptors, sodium channels, and $\gamma$-aminobutyric acid (GABA)ergic, opioid, serotonergic and noradrenergic function. In addition, SCI results in glial activation and increased cytokine and prostaglandin release as well as structural reorganization of inputs in the dorsal horn of the spinal cord (for reviews of contributing physiological spinal mechanisms see Hains and Waxman $^{30}$ and Yezierski ${ }^{31}$ ).

\section{Brain mechanisms}

Despite the evidence supporting the concept of an 'irritated focus' in the spinal cord close to the site of damage, neuropathic pain may continue despite removal of a section of the spinal cord above the level of injury as demonstrated by Melzack and Loeser. ${ }^{32}$ This raises the question as to whether changes in brain structures may also contribute to the development of pain. A number of studies in animals and humans have demonstrated brain changes associated with the presence of neuropathic pain following SCI although the precise link between these changes and the development of pain remains a matter of debate. The brain changes described include alterations in thalamic neuronal 
firing, ${ }^{33}$ expression of sodium channels, ${ }^{34}$ biochemical changes $^{35}$ and changes in thalamic perfusion or activity. ${ }^{36}$

Recent work by our own group has focused on the investigation of brain changes associated with neuropathic pain following SCI. One group of studies has focused on electrical changes that may contribute to the development of pain. It has been suggested that neuropathic pain may be because of abnormal brain rhythms that reflect altered firing of thalamic and cortical circuits. This was further supported by our own findings in basic studies of abnormal rhythmic activity in thalamic neurons following SCI. ${ }^{37}$ To investigate this further in clinical studies, we used electroencephalography (EEG) to determine whether there was an alteration in the brain wave activity of people who have SCI and pain. We found that although people with SCI had alterations in activity, people with pain and SCI had significant changes with 'slowing' of the EEG activity and a reduction in the frequency in the $\alpha$ - and $\theta$ - band. ${ }^{38}$ This is consistent with the concept of a thalamocortical dysrhythmia that is associated with disinhibition and generation of pain in abnormally functioning brain circuits.

Another set of studies that we have performed has focused on possible plastic or reorganizational changes in the brain that may contribute to the development of pain. In a landmark study, Flor et al. ${ }^{39}$ demonstrated that neuropathic pain following amputation was associated with a shift in cortical representation of the lip towards the denervated hand region and the degree of shift correlated with pain intensity. Given the parallels between neuropathic pain following amputation and SCI, we followed up on this finding by using functional magnetic resonance imaging to determine whether there is a shift in cortical representation of the body region neighbouring the site of deafferentation in complete paraplegic subjects with neuropathic pain. ${ }^{40}$ Indeed, this was the case. When the lip, thumb and little finger were stimulated mechanically, there was a significant shift in the region of brain activation following stimulation of the little finger but not the lip or the thumb. Thus, the region of brain activated following stimulation of the little finger had shifted towards the region that would normally be activated following stimulation of the lower part of the body. Although there was a small shift in subjects with SCI but without pain, there was statistically significant shift in subjects with SCI and pain that also correlated with pain intensity. Although it is difficult to attribute causality, it clearly demonstrates a link between plastic changes in the brain and the presence of neuropathic pain following SCI.

\section{Management of neuropathic pain following $\mathrm{SCl}$}

\section{General principles}

Given the physiological changes described above, the treatment of neuropathic SCI pain has attempted to address the abnormalities occurring at peripheral, spinal and brain levels in the hope that this will abolish or at least significantly reduce the pain. This article will not attempt to exhaustively list all current pharmacological interventions and fairly recent reviews of pharmacological treatment can be found elsewhere. ${ }^{41,42}$ Instead, it will endeavour to provide a broad overview of pharmacological and nonpharmacological treatments based on our current understanding of mechanisms.

\section{Surgical approaches}

Surgical approaches usually relieve pain by reversing structural problems. For example, surgery may be used to address nerve root or peripheral nerve compression, tethering of nerve roots and syrinx formation. Orthopaedic and neurosurgical procedures that stabilize the spine immediately after trauma and decompress impinged nerve roots can be very effective at eliminating the pains of instability or nerve root compression. ${ }^{43}$ If it is not possible to address a structural problem, surgical approaches attempt to deal with the pain by destroying or disconnecting the site of abnormal neuronal activity.

Several uncontrolled studies have been performed to examine efficacy of surgical approaches but have produced variable results. Dorsal root entry zone (DREZ) lesioning is a procedure that aims to destroy hyperactive nerve cells in the dorsal horn close to the level of injury. The procedure may provide relief of neuropathic pain but the reported efficacy of DREZ lesions varies. Most studies indicate that $50-85 \%$ will obtain good $(>50 \%)$ relief of their pain ${ }^{43-45}$ with suggested better results in those with at-level neuropathic pain. ${ }^{44}$ Others have suggested that DREZ lesioning guided by intramedullary recordings of spontaneous and C-fibre evoked electrical hyperactivity may be effective in relieving both at- and below-level neuropathic pain. ${ }^{46,47}$

Cordotomy or cordomyelotomy has been used to a limited extent and some reports suggest effectiveness in a subgroup of patients. ${ }^{48,49}$ Pagni and Canavero ${ }^{49}$ described three paraplegic patients treated with cordomyelotomy for the treatment of neuropathic SCI pain. Two of these had excellent results after more than 10 years. The use of cordectomy as a pain-relieving measure is controversial. Despite reports of alleviation of neuropathic pain in some patients following transection of the spinal cord at a higher level, ${ }^{50}$ a number of reports suggest that even with complete anatomical section of the spinal cord there is either poor or no relief of below-level neuropathic pain. ${ }^{23,32,48}$

\section{Pharmacological options}

As described previously, pain may be very broadly attributable to increased neuronal excitability. This increased excitability may be due to either an enhancement of excitatory mechanisms or a loss or reduction in inhibition. Agents such as local anaesthetics and NMDA antagonists aim to reduce the abnormal excitability associated with aberrant sodium channel or NMDA receptor function. Drugs such as opioids, antiepileptics and antidepressant medications often act by increasing inhibitory mechanisms although many antiepileptics and tricyclic antidepressants are broadspectrum agents with wide modes of action that may both increase inhibition and decrease excitation. Unfortunately, despite the large number of drugs available, adequate pain control is often difficult to achieve. Most studies indicate 
that the best available medications will only provide around one-third of people with a $50 \%$ reduction in their pain.

Local anaesthetics may be helpful and parenteral administration of the sodium channel blocker lidocaine has been shown to be effective in the treatment of neuropathic pain following SCI. ${ }^{51-54}$ However, parenteral administration is generally not practical as an ongoing treatment and unfortunately no orally available sodium channel blocker appears to be consistently effective. Mexiletine, an oral congener of lidocaine, was found to be no better than placebo in a controlled trial. ${ }^{55}$ The NMDA receptor is another target for increased excitability and parenteral administration of the NMDA receptor antagonist ketamine was demonstrated to be more effective than placebo in reducing below-level neuropathic SCI pain. ${ }^{56}$ However, as with lidocaine, long-term administration remains a problem and there are no oral alternatives that have been demonstrated to be beneficial.

Although opioids are sometimes regarded as relatively ineffective for the treatment of neuropathic pain, there is reasonably strong evidence to indicate the ability of opioids to produce a significant reduction in neuropathic SCI pain. Two randomized controlled trials involving intravenous morphine ${ }^{57}$ and alfentanil ${ }^{56}$ have been conducted that demonstrated a significant reduction in neuropathic pain following SCI. However these responses using parenteral agents are short term and parenteral opioid administration is not suitable for long-term management. The evidence for use of specific oral or transdermal opioids in the treatment of neuropathic SCI pain is very limited and side effects such as constipation as well as tolerance and dependence are major problems.

Antiepileptic drugs are widely used in the treatment of neuropathic SCI pain. Both valproate and carbamazepine have been used for some time. Although subject numbers were small, the only published controlled trial using valproate failed to demonstrate any significant difference from placebo. ${ }^{58}$ The evidence to support the use of carbamazepine is also very limited. More recently, gabapentin has entered into widespread clinical use with anecdotal evidence to support its use. However, specific evidence for effectiveness in the treatment of neuropathic SCI pain is relatively slim and confined to small studies ${ }^{59-61}$ with a recent randomized controlled trial failing to find any significant benefit from gabapentin. ${ }^{62}$ Pregabalin is a newer anticonvulsant that has the same mode of action as gabapentin. Evidence from one fairly large trial and one smaller trial provide specific support for its effectiveness in the treatment of neuropathic pain following SCI. ${ }^{63,64}$ Several of the newer antiepileptics including lamotrigine and topiramate have been used and trialled in neuropathic SCI pain but evidence is weak with a negative outcome for lamotrigine (except for a subgroup with incomplete injuries) ${ }^{65}$ and a positive outcome for topiramate but in a small study. ${ }^{66}$

Like antiepileptics, tricyclic antidepressants are widely used in the management of neuropathic pain conditions but with little direct evidence for effectiveness in the treatment of neuropathic SCI pain. One controlled study with amitriptyline treating a group of people with both musculoskeletal and neuropathic SCI pain found no significant benefit over placebo. ${ }^{67}$ Another randomized controlled study found a significant benefit in those with neuropathic SCI pain but only in a subgroup with higher scores for depression. ${ }^{62}$ The serotonin reuptake inhibitor and 5-HT receptor antagonist, trazodone, has been shown in one randomized controlled trial to be no better than placebo. ${ }^{68}$ There is anecdotal evidence to support the use of mixed serotonin and noradrenaline reuptake inhibitors such as venlafaxine and duloxetine but, as yet, there are no controlled trials.

If oral administration fails to provide adequate analgesia, spinal drug administration may be considered. Evidence of efficacy is confined to case series and limited controlled trials. The approach is invasive and should not be considered until more conservative measures have been thoroughly trialled. Combined intrathecal administration of morphine and clonidine was found to produce a short-term reduction in pain in a group of people with neuropathic SCI pain. ${ }^{69}$ Intrathecal baclofen is effective in managing spasticity and spasm-related pain secondary to SCI. However, the effect of baclofen on neuropathic SCI pain is less clear with conflicting results in controlled trials. ${ }^{70}$ Spinal anaesthesia with subarachnoid lidocaine may also provide analgesia in SCI neuropathic pain. However, the effect of spinal anaesthesia is of course only temporary, limiting its clinical usefulness.

\section{Neurostimulation}

Neurostimulation techniques such as transcutaneous electrical nerve stimulation (TENS) and acupuncture may be effective for some people with neuropathic pain. ${ }^{71}$ However positive evidence of efficacy is limited, particularly with below-level neuropathic pain. ${ }^{72,73}$ Other neurostimulation techniques are very invasive with limited evidence of efficacy. Spinal cord stimulation may provide relief although a greater effect is obtained in those with at-level neuropathic pain and incomplete lesions. ${ }^{74}$ Deep brain stimulation is highly invasive and does not seem to provide long-term pain relief in SCI pain. ${ }^{75}$ Transcranial and epidural motor cortex stimulation have been tested in a few SCI pain patients with varying results. ${ }^{76} \mathrm{~A}$ recent study using transcranial direct current stimulation demonstrated a short-term but significant reduction in pain following a 5-day treatment trial and suggests the possibility of an alternative effective noninvasive approach. ${ }^{77}$

\section{Psychological and environmental management}

A variety of approaches are available for managing psychological and environmental contributors to pain and distress. Pharmacological strategies such as anxiolytic and antidepressant therapy and non-pharmacological strategies such as cognitive behavioural therapy may be used. ${ }^{78,79}$ The effectiveness of a cognitive behavioural approach in the management of neuropathic SCI pain has been examined with significant improvements in mood although not pain. ${ }^{79}$ Other approaches such as relaxation and desensitization techniques may also be of benefit.

An interesting avenue that has emerged recently is the use of movement imagery to modify neuropathic SCI pain. In 
one study that used a visual illusion of walking, a significant reduction in neuropathic pain was noted in people following cauda equina injury. ${ }^{80}$ However, these positive results need to be balanced against a study of our own in which imagined ankle movements following complete SCI resulted in an increase in pain and unpleasant phantom sensations. ${ }^{81}$ The reason for the difference in findings is still uncertain but may be because of differences in the level and completeness of injury, with the positive responders having incomplete cauda equina injuries. Nevertheless, the use of cognitive strategies such as movement imagery presents an interesting possible alternative approach and may be helpful in a certain subgroup of patients.

\section{Looking ahead}

What does the future hold for the treatment of pain following SCI and particularly neuropathic SCI pain where we currently have so few options? The mechanisms described above suggest the possibility of various approaches that may be beneficial. As described, we have now identified specific physiological changes that may be amenable to treatment with more selective and effective agents. One of the problems with current pharmacotherapy is that agents are either ineffective or have unacceptable side effects. However, a number of pharmacological targets have been identified recently that present possible sites for effective intervention using novel therapeutic agents with an improved side effect profile. For example, the discovery of the importance of sodium channels in the development of neuropathic pain, including neuropathic SCI pain, suggests that sodium channel blocking agents may be effective. The use of agents such as mexiletine has been disappointing with limited evidence of effectiveness. However, the discovery of the upregulation of specific sodium channel subtypes and the concerted effort that is now being focused on the development of specific subtype blockers offers the hope of therapeutic effect without the side effects associated with non-selective agents. These or other agents with high efficacy and high selectivity offer hope for the development of drugs that are both effective and well tolerated.

Neurostimulation provides another possible non-pharmacological approach to the treatment of neuropathic SCI pain. Peripheral stimulation techniques such as TENS and acupuncture have enjoyed only moderate success in reducing pain and central stimulation techniques such as deep brain stimulation and epidural motor cortex stimulation are highly invasive with relatively poor long-term outcomes. However, the promising results of the trial by Fregni et al. ${ }^{77}$ using low-amplitude, direct current stimulation suggest the potential benefit of stimulation of the cortex using a noninvasive approach. Further studies evaluating long-term outcomes will be very valuable in determining whether this presents an effective and sustained approach to the relief of neuropathic SCI pain. It also provides further support for the use of other non-invasive neurostimulation techniques such as transcutaneous magnetic stimulation, another potential approach that is yet to be fully explored.
Lastly, we are only just beginning to uncover the power of the mind and its ability to modulate pain. It has long been known that people with neuropathic pain following SCI often report substantial relief of pain with distraction or focusing on an absorbing task. As described above, it appears that SCI pain is associated with central changes including alterations in neuronal firing in brain structures and neuroplastic changes. Recent studies clearly demonstrate that neuropathic pain can be modified using cognitive approaches such as movement imagery, visual illusions or sensory discrimination training. These techniques may act by modifying central processes involved in pain perception. We still have little information regarding the mechanisms, the specific types of pain that may respond to these interventions and the specific components of these tasks that produce an effect. However, there is a tantalizing suggestion that approaches such as movement imagery, visual illusions or biofeedback using EEG or real time fMRI may be powerful tools that can be further developed and refined to attain a significant reduction in pain.

\section{Acknowledgements}

Carrying out the studies of our group mentioned in this review would not have been possible without the support, advice, assistance and hard work of my mentors, colleagues and students that I have had the pleasure of working with as well as the many people with SCI and pain who have so generously and willingly given their time to take part. I also acknowledge the financial support of the NSW Government Spinal Cord Injury and Other Neurological Conditions Research Grants Program who currently supports our work.

\section{References}

1 Siddall PJ, McClelland JM, Rutkowski SB, Cousins MJ. A longitudinal study of the prevalence and characteristics of pain in the first 5 years following spinal cord injury. Pain 2003; 103: 249-257.

2 Widerström-Noga EG, Felipe-Cuervo E, Broton JG, Duncan RC, Yezierski RP. Perceived difficulty in dealing with consequences of spinal cord injury. Arch Phys Med Rehabil 1999; 80: 580-586.

3 Jensen MP, Kuehn CM, Amtmann D, Cardenas DD. Symptom burden in persons with spinal cord injury. Arch Phys Med Rehabil 2007; 88: 638-645.

4 Störmer S, Gerner HJ, Grüninger W, Metzmacher K, Föllinger S, Wienke C et al. Chronic pain/dysaesthesiae in spinal cord injury patients: results of a multicentre study. Spinal Cord 1997; 35: 446-455.

5 Richards JS, Meredith RL, Nepomuceno C, Fine PR, Bennett G. Psycho-social aspects of chronic pain in spinal cord injury. Pain 1980; 8: 355-366.

6 Summers JD, Rapoff MA, Varghese G, Porter K, Palmer RE. Psychosocial factors in chronic spinal cord injury pain. Pain 1991; 47: 183-189.

7 Norrbrink Budh C, Hultling C, Lundeberg T. Quality of sleep in individuals with spinal cord injury: a comparison between patients with and without pain. Spinal Cord 2005; 43: 85-95.

8 Rose M, Robinson JE, Ells P, Cole JD. Pain following spinal cord injury: results from a postal survey. Pain 1988; 34: 101-102.

9 Widerström-Noga EG, Duncan R, Felipe-Cuervo E, Turk DC. Assessment of the impact of pain and impairments associated with spinal cord injuries. Arch Phys Med Rehabil 2002; 83: 395-404. 
10 Widerström-Noga EG, Felipe-Cuervo E, Yezierski RP. Chronic pain after spinal injury: interference with sleep and daily activities. Arch Phys Med Rehabil 2001; 82: 1571-1577.

11 Putzke JD, Richards JS, Hicken BL, DeVivo MJ. Interference due to pain following spinal cord injury: important predictors and impact on quality of life. Pain 2002; 100: 231-242.

12 Ravenscroft A, Ahmed YS, Burnside IG. Chronic pain after SCI. A patient survey. Spinal Cord 2000; 38: 611-614.

13 Westgren N, Levi R. Quality of life and traumatic spinal cord injury. Arch Phys Med Rehabil 1998; 79: 1433-1439.

14 Anke AGW, Stenehjem AE, Stanghelle JK. Pain and life quality within 2 years of spinal cord injury. Paraplegia 1995; 33: 555-559.

15 Rintala D, Loubser PG, Castro J, Hart KA, Fuhrer MJ. Chronic pain in a community-based sample of men with spinal cord injury: prevalence, severity, and relationship with impairment, disability, handicap, and subjective well-being. Arch Phys Med Rehabil 1998; 79: 604-614.

16 Budh CN, Osteraker A-L. Life satisfaction in individuals with a spinal cord injury and pain. Clin Rehabil 2007; 21: 89-96.

17 Melzack R, Wall PD. Pain mechanisms: a new theory. Science 1965; 150: 971-979.

18 Melzack R. The John J Bonica Distinguished Lecture: the gate control theory 25 years later: new perspectives in phantom limb pain. In: Bond MR, Charlton JE, Woolf CJ (eds). Pain Research and Clinical Management, Proceedings of the VIth World Congress on Pain. Elsevier: Amsterdam, 1991, pp. 9-21.

19 Feiling A. Central pain in spinal cord lesions. Proc R Soc Med 1937; 31: 39-48.

20 Siddall PJ, Yezierski RP, Loeser JD. Taxonomy and epidemiology of spinal cord injury pain. In: Yezierski RP, Burchiel KJ (eds). Spinal Cord Injury Pain: Assessment, Mechanisms, Management Progress in Pain Research and Management, Vol 23, IASP Press: Seattle, 2002, pp 9-24.

21 Bryce TN, Budh CN, Cardenas DD, Dijkers M, Felix ER, Finnerup NB et al. Pain after spinal cord injury: an evidence-based review for clinical practice and research. Report of the National Institute on Disability and Rehabilitation Research Spinal Cord Injury Measures meeting. J Spinal Cord Med 2007; 30: 421-440.

22 Widerstrom-Noga E, Biering-Sorensen F, Bryce T, Cardenas DD, Finnerup NB, Jensen MP et al. The International Spinal Cord Injury Pain Basic Data Set. Spinal Cord 2008 (advance online publication 3 June 2008; doi:10.1038/sc.2008.64).

23 Davis L. Treatment of spinal cord injuries. AMA Arch Surg 1954; 69: 488-495.

24 Pollock LJ, Brown M, Boshes B, Finkelman I, Chor H, Arieff AJ et al. Pain below the level of injury of the spinal cord. AMA Arch Neurol Psychiatry 1951; 65: 319-322.

25 Sherwood AM, Dimitrijevic MR, McKay WB. Evidence of subclinical brain influence in clinically complete spinal cord injury: discomplete SCI. J Neurol Sci 1992; 110: 90-98.

26 Loeser JD, Ward AA, White LE. Chronic deafferentation of human spinal cord neurons. J Neurosurg 1968; 29: 48-50.

27 Hao JX, Xu XJ, Yu YX, Seiger A, Wiesenfeld-Hallin Z. Transient spinal cord ischaemia induces temporary hypersensitivity of dorsal horn wide dynamic range neurons to myelinated, but not unmyelinated, fiber input. J Neurophysiol 1992; 68: 384-391.

28 Yezierski RP, Park SH. The mechanosensitivity of spinal sensory neurons following intraspinal injections of quisqualic acid in the rat. Neurosci Lett 1993; 157: 115-119.

29 Christensen MD, Everhart AW, Pickelman JT, Hulsebosch CE. Mechanical and thermal allodynia in chronic central pain following spinal cord injury. Pain 1996; 68: 97-107.

30 Hains BC, Waxman SG. Sodium channel expression and the molecular pathophysiology of pain after SCI. Prog Brain Res 2007; 161: 195-203.

31 Yezierski RP. Pathophysiology and animal models of spinal cord injury pain. In: Yezierski RP, Burchiel KJ (eds). Spinal Cord Injury Pain: Assessment, Mechanisms, Management Progress in Pain Research and Management, Vol. 23, IASP Press: Seattle, 2002, pp 117-136.

32 Melzack R, Loeser JD. Phantom body pain in paraplegics: evidence for a central 'pattern generating mechanism' for pain. Pain 1978; 4: 195-210.
33 Lenz FA, Kwan HC, Dostrovsky JO, Tasker RR. Characteristics of the bursting pattern of action potentials that occurs in the thalamus of patients with central pain. Brain Res 1989; 496: 357-360.

34 Hains BC, Saab CY, Waxman SG. Changes in electrophysiological properties and sodium channel $\mathrm{Na}(\mathrm{v}) 1.3$ expression in thalamic neurons after spinal cord injury. Brain 2005; 128: 2359-2371.

35 Pattany PM, Yezierski RP, Widerström-Noga EG, Bowen BC, Martinez-Arizala A, Garcia BR et al. Proton magnetic resonance spectroscopy of the thalamus in patients with chronic neuropathic pain after spinal cord injury. Am J Neuroradiol 2002; 23: 901-905.

36 Ness TJ, San Pedro EC, Richards JS, Kezar L, Liu HG, Mountz JM. A case of spinal cord injury-related pain with baseline rCBF brain SPECT imaging and beneficial response to gabapentin. Pain 1998; 78: $139-143$.

37 Gerke MB, Duggan AW, Xu L, Siddall PJ. Thalamic neuronal activity in rats with mechanical allodynia following contusive spinal cord injury. Neuroscience 2003; 117: 715-722.

38 Boord P, Siddall PJ, Tran Y, Herbert D, Middleton J, Craig A. Electroencephalographic slowing and reduced reactivity in neuropathic pain following spinal cord injury. Spinal Cord 2007; 46: $118-123$.

39 Flor H, Elbert T, Knecht S, Wienbruch C, Pantev C, Birbaumer N et al. Phantom-limb pain as a perceptual correlate of cortical reorganization following arm amputation. Nature 1995; 375: 482-484.

40 Wrigley PJ, Press SR, Gustin SM, Macefield VG, Gandevia SC, Cousins MJ et al. Neuropathic pain and primary somatosensory cortex reorganization following spinal cord injury. Pain (in press).

41 Finnerup NB, Johannesen IL, Sindrup SH, Bach FW, Jensen TS, Burchiel KJ et al. Pharmacological treatment of spinal cord injury pain. In: Yezierski RP, Burchiel KJ (eds). Spinal Cord Injury Pain: Assessment, Mechanisms, Management Progress in Pain Research and Management, Vol. 23 IASP Press: Seattle, 2002, pp 341-351.

42 Wrigley PJ, Siddall PJ. Pharmacological interventions for neuropathic pain following spinal cord injury: an update. Top Spinal Cord Inj Rehabil 2007; 13: 58-71.

43 Friedman AH, Nashold Jr BS. DREZ lesions for relief of pain related to spinal cord injury. J Neurosurg 1986; 65: 465-469.

44 Sindou M, Mertens P, Wael M. Microsurgical DREZotomy for pain due to spinal cord and/or cauda equina injuries: long-term results in a series of 44 patients. Pain 2001; 92: 159-171.

45 Powers SK, Adams JE, Edwards MS, Boggan JE, Hosobuchi Y. Pain relief from dorsal root entry zone lesions made with argon and carbon dioxide microsurgical lasers. J Neurosurg 1984; 61: 841-847.

46 Edgar RE, Best LG, Quail PA, Obert AD. Computer-assisted DREZ microcoagulation: posttraumatic spinal deafferentation pain. J Spinal Disord 1993; 6: 48-56.

47 Falci S, Best L, Bayles R, Lammertse D, Starnes C. Dorsal root entry zone microcoagulation for spinal cord injury-related central pain: operative intramedullary electrophysiological guidance and clinical outcome. J Neurosurg 2002; 97: 193-200.

48 Tasker RR, DeCarvalho GTC, Dolan EJ. Intractable pain of spinal cord origin: clinical features and implications for surgery. J Neurosurg 1992; 77: 373-378.

49 Pagni CA, Canavero S. Cordomyelotomy in the treatment of paraplegia pain - experience in two cases with long-term results. Acta Neurol Belg 1995; 95: 33-36.

50 Nashold BS. Paraplegia and pain. In: Nashold BS, Ovelmen-Levitt J (eds). Deafferentation Pain Syndromes: Pathophysiology and Treatment. Raven: New York, 1991, pp 301-319.

51 Backonja M, Gombar KA. Response of central pain syndromes to intravenous lidocaine. J Pain Symptom Manage 1992; 7: 172-178.

52 Attal N, Gaud V, Brasseur L, Dupuy M, Guirimand F, Parker F et al. Intravenous lidocaine in central pain: a double-blind, placebo-controlled, psychophysical study. Neurology 2000; 54: 564-574.

53 Finnerup NB, Biering-Sorensen F, Johannesen IL, Terkelsen AJ, Juhl GI, Kristensen AD et al. Intravenous lidocaine relieves spinal 
cord injury pain: a randomized controlled trial. Anesthesiology 2005; 102: 1023-1030.

54 Kvarnstrom A, Karlsten R, Quiding H, Gordh T. The analgesic effect of intravenous ketamine and lidocaine on pain after spinal cord injury. Acta Anaesthesiol Scand 2004; 48: 498-506.

55 Chiou-Tan FY, Tuel SM, Johnson JC, Priebe MM, Hirsh DD, Strayer JR. Effect of mexiletine on spinal cord injury dysesthetic pain. Am J Phys Med Rehabil 1996; 75: 84-87.

56 Eide PK, Stubhaug A, Stenehjem AE. Central dysesthesia pain after traumatic spinal cord injury is dependent on $\mathrm{N}$-methylD-aspartate receptor activation. Neurosurgery 1995; 37: 1080-1087.

57 Attal N, Guirimand F, Brasseur L, Gaude V, Chauvin M, Bouhassira D. Effects of IV morphine in central pain-a randomized placebo- controlled study. Neurology 2002; 58: 554-563.

58 Drewes AM, Andreasen A, Poulsen LH. Valproate for treatment of chronic central pain after spinal cord injury. A double-blind cross-over study. Paraplegia 1994; 32: 565-569.

59 Levendoglu F, Ogun CO, Ozerbil O, Ogun TC, Ugurlu H. Gabapentin is a first line drug for the treatment of neuropathic pain in spinal cord injury. Spine 2004; 29: 743-751.

60 Tai Q, Kirshblum S, Chen B, Millis S, Johnston M, DeLisa JA. Gabapentin in the treatment of neuropathic pain after spinal cord injury: a prospective, randomized, double-blind, crossover trial. I Spinal Cord Med 2002; 25: 100-105.

61 Putzke JD, Richards JS, Kezar L, Hicken BL, Ness TJ. Long-term use of gabapentin for treatment of pain after traumatic spinal cord injury. Clin J Pain 2002; 18: 116-121.

62 Rintala DH, Holmes SA, Courtade D, Fiess RN, Tastard LV, Loubser PG. Comparison of the effectiveness of amitriptyline and gabapentin on chronic neuropathic pain in persons with spinal cord injury. Arch Phys Med Rehabil 2007; 88: 1547-1560.

63 Siddall PJ, Cousins MJ, Otte A, Griesing T, Chambers R, Murphy TK. Pregabalin in central neuropathic pain associated with spinal cord injury: A placebo-controlled trial. Neurology 2006; 67: 1792-1800.

64 Vranken JH, Dijkgraaf MGW, Kruis MR, van der Vegt MH, Hollmann MW, Heesen M. Pregabalin in patients with central neuropathic pain: a randomized, double-blind, placebocontrolled trial of a flexible-dose regimen. Pain 2008; 136: 150-157.

65 Finnerup NB, Sindrup SH, Flemming WB, Johannesen IL, Jensen TS. Lamotrigine in spinal cord injury pain: a randomized controlled trial. Pain 2002; 96: 375-383.

66 Harden RN, Brenman E, Saltz S, Houle TT. Topiramate in the management of spinal cord injury pain: a double-blind, randomized, placebo-controlled pilot study. In: Yezierski RP, Burchiel KJ (eds). Spinal Cord Injury Pain: Assessment, Mechanisms, Management Progress in Pain Research and Management, Vol. 23. IASP Press: Seattle, 2002, pp 393-407.

67 Cardenas DD, Warms CA, Turner JA, Marshall H, Brooke MM, Loeser JD. Efficacy of amitriptyline for relief of pain in spinal cord injury: results of a randomized controlled trial. Pain 2002; 96: 365-373.

68 Davidoff G, Guarracini M, Roth E, Sliwa J, Yarkony G. Trazodone hydrochloride in the treatment of dysesthetic pain in traumatic myelopathy: a randomized, double-blind, placebo-controlled study. Pain 1987; 29: 151-161.

69 Siddall PJ, Molloy AR, Walker S, Mather LE, Rutkowski SB, Cousins MJ. The efficacy of intrathecal morphine and clonidine in the treatment of pain after spinal cord injury. Anesth Analg 2000; 91: 1493-1498.

70 Loubser PG, Akman NM. Effects of intrathecal baclofen on chronic spinal cord injury pain. J Pain Symptom Manage 1996; 12: 241-247.

71 Norrbrink Budh C, Lundeberg T. Non-pharmacological painrelieving therapies in individuals with spinal cord injury: a patient perspective. Complement Ther Med 2004; 12: 189-197.

72 Nayak S, Shiflett SC, Schoenberger NE, Agostinelli S, Kirshblum S, Averill A et al. Is acupuncture effective in treating chronic pain after spinal cord injury? Arch Phys Med Rehabil 2001; 82: 1578-1586.

73 Rapson LM, Wells N, Pepper J, Majid N, Boon H. Acupuncture as a promising treatment for below-level central neuropathic pain: a retrospective study. J Spinal Cord Med 2003; 26: 21-26.

74 Cioni B, Meglio M, Pentimalli L, Visocchi M. Spinal cord stimulation in the treatment of paraplegic pain. J Neurosurg 1995; 82: 35-39.

75 Finnerup NB, Yezierski RP, Sang CN, Burchiel KJ, Jensen TS. Treatment of spinal cord injury pain. Pain Clin Updates 2001; 9: $1-6$.

76 Nguyen JP, Lefaucheur JP, Decq P, Uchiyama T, Carpentier A, Fontaine $\mathrm{D}$ et al. Chronic motor cortex stimulation in the treatment of central and neuropathic pain. Correlations between clinical, electrophysiological and anatomical data. Pain 1999; 82: 245-251.

77 Fregni F, Boggio PS, Lima MC, Ferreira MJ, Wagner T, Rigonatti SP et al. A sham-controlled, phase II trial of transcranial direct current stimulation for the treatment of central pain in traumatic spinal cord injury. Pain 2006; 122: 197-209.

78 Craig AR, Hancock K, Dickson H, Chang E. Long-term psychological outcomes in spinal cord injured persons: results of a controlled trial using cognitive behavior therapy. Arch Phys Med Rehabil 1997; 78: 33-38.

79 Budh CN, Kowalski J, Lundeberg T. A comprehensive pain management programme comprising educational, cognitive and behavioural interventions for neuropathic pain following spinal cord injury. J Rehabil Med 2006; 38: 172-180.

80 Moseley GL. Using visual illusion to reduce at-level neuropathic pain in paraplegia. Pain 2007; 130: 294-298.

81 Gustin SM, Wrigley PJ, Gandevia SC, Middleton JW, Henderson LA, Siddall PJ. Movement imagery increases pain in people with neuropathic pain following complete thoracic spinal cord injury. Pain 2008; 137: 237-244. 